\title{
8
}
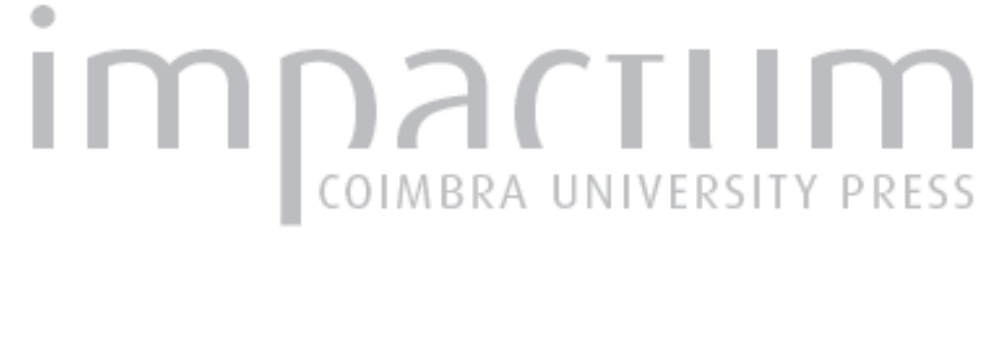

\section{Epistemología e educación: síntsis general y educacíon artística en la génesis del auto-evaluación, conciencia y autonomía}

Autor(es): $\quad$ Cunha, Sergio Gonçalves da

Publicado por: $\begin{aligned} & \text { Universidade Católica de Petrópolis; Instituto Brasileiro de Informação } \\ & \text { em Ciência e Tecnologia }\end{aligned}$

URL

persistente:

URI:http://hdl.handle.net/10316.2/33072

DOI:

DOI:http://dx.doi.org/10.14195/1984-6754_2-2_5

Accessed : $\quad$ 26-Apr-2023 12:21:21

A navegação consulta e descarregamento dos títulos inseridos nas Bibliotecas Digitais UC Digitalis, UC Pombalina e UC Impactum, pressupõem a aceitação plena e sem reservas dos Termos e Condições de Uso destas Bibliotecas Digitais, disponíveis em https://digitalis.uc.pt/pt-pt/termos.

Conforme exposto nos referidos Termos e Condições de Uso, o descarregamento de títulos de acesso restrito requer uma licença válida de autorização devendo o utilizador aceder ao(s) documento(s) a partir de um endereço de IP da instituição detentora da supramencionada licença.

Ao utilizador é apenas permitido o descarregamento para uso pessoal, pelo que o emprego do(s) título(s) descarregado(s) para outro fim, designadamente comercial, carece de autorização do respetivo autor ou editor da obra.

Na medida em que todas as obras da UC Digitalis se encontram protegidas pelo Código do Direito de Autor e Direitos Conexos e demais legislação aplicável, toda a cópia, parcial ou total, deste documento, nos casos em que é legalmente admitida, deverá conter ou fazer-se acompanhar por este aviso.

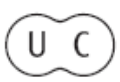



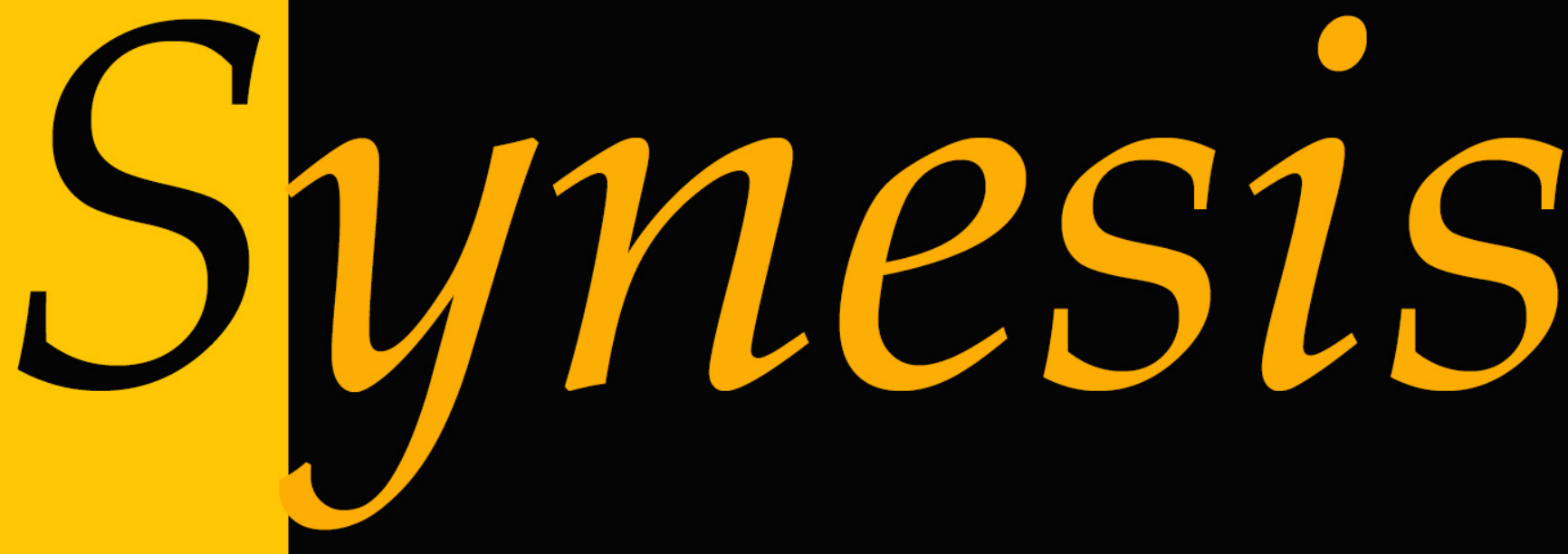

Revista do Centro de Teologia e Humanidades ISSN 1984-6754

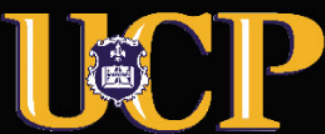




\title{
EPISTEMOLOGÍA Y EDUCACIÓN:
}

\section{SÍNTESIS GENERAL Y EDUCACIÓN ARTÍSTICA EN LA GÉNESIS DEL AUTO-EVALUACIÓN, CONCIENCIA Y AUTONOMÍA}

\author{
Sergio Gonçalves da Cunha ${ }^{1}$
}

Resumen: Este texto promueve un ejercicio de lectura y reflexión sobre algunos autores, conceptos elementales y teorías en los campos de epistemología y educación, migrando posteriormente para un breve abordaje sobre la posibilidad metodológica cualitativa permeada por la Educación Artística. Tenemos fuentes bibliográficos centrados especialmente sobre los contenidos de Epistemología, Filosofía, Educación, Arte e Aprendizaje Transformativo. La temática explicitada busca abrir espacios para posteriores discusiones que puedan contemplar un mejor análisis sobre los recursos didácticos y metodológicos para la enseñanza del Arte a través de variados lenguajes que busquen el foco en la formación del individuo como ser social.

Palabras llave: epistemología, educación, metodología cualitativa, Educación Artística, Aprendizaje Transformativo y autonomía.

\begin{abstract}
This text promotes a reading exercise and reflection on some authors, elementary concepts and theories in the fields of the epistemology and education, migrating later for an abbreviation approach about the qualitative methodological possibility permeated by the Artistic Education. We have as base bibliographical sources especially centered in the contents of Epistemology, Philosophy, Education, Art and Transformative Learning. The theme explicated tries to open space for subsequent discussions that can contemplate a
\end{abstract} 1 Doctorando en Humanidades y Artes por la Universidad Nacional de Rosario - UNR. Email:
sgcunha2@yahoo.com.br; sergio.cunha@ucp.br; sergiocunha1@hotmail.com 
better analysis about didactic and methodological resources for the teaching of Art through varied languages that look for the focus in the individual's formation how social person.

Keywords: epistemology, education, qualitative methodological, Art Education, Transformative Learning and autonomy.

\section{Verdad, conocimiento e intenciones}

A la filosofía de la ciencia (Epistemología) se la considera sustancialmente como la "ciencia de las ciencias" por lo que hay que recibir por lo menos igual cuidado en relación a las demás ciencias del hombre, eso por poseer, por naturaleza, las bases fundamentales con las cuales se discute el conocimiento humano.

Hay diversas ciencias que de variadas formas cohabitan los espacios de investigación sobre la esencia humana. Epistemología y Ontología por ejemplo son estudios paralelos aunque independientes. La posición de dichos estudios basados en ciencia, conocimiento y posibles verdades pueden ayudar a contestar a diversas cuestiones despertadas por las necesidades y curiosidades del ser pensante.

No existe una sola "Epistemología” pero sí "Epistemologías", y son diversas, ligadas a otros tantos problemas y necesidades de la humanidad. Ejemplos: Epistemología de la vida, de la física, de la química, etc., que reaccionan de acuerdo con las especificidades de cada área en la búsqueda por los cimientos sobre los cuales se basan sus conceptos elementales.

Aun ejemplificando, los franceses afirmaban que la ciencia está íntimamente ligada a la filosofía y que un determinado paradigma es lo que condiciona a esta o aquella filosofía. En otro sentido, los positivistas decían que la ciencia está basada en teoría pero lo que hoy se percibe es que la realidad está más allá de lo que entonces se sustentaba pues la ciencia es más compleja en su práctica.

En lo que toca a la Ontología, su foco de investigación y sentido se vuelve para el ser y trata de la dimensión de la propia existencia. Es un concepto relativista que no se 
refiere al espacio físico y que también se constituye como elemento de gran envergadura si agregado a las ciencias sociales.

Las ciencias sociales son absolutamente variables. Su actuación involucra un amplio grupo de conductas y el objeto (sujeto) igual se pone en un complejo de conductas. Una conducta es, muchas veces, conocida como manifestación del inconsciente como por ejemplo lo vemos con los histéricos. Por otro lado, la conducta bien como los estudios sociológicos es holística, por lo tanto nada puede ser despreciado de aquello que la circunda y que hace parte del universo del objeto de estudios de las ciencias sociales: el sujeto.

Vivimos en un mundo social de tradiciones, conflictos, búsquedas y valores, hipótesis y singularidades que deben ser también analizadas desde el punto de vista sociológico.

Los sentidos no pueden ser verificados bajo un prisma de objetividad y de forma analítica. De igual manera no pueden ser pura o simplemente mensurados en axiomas cartesianos o matemáticos. Al hablar de paradigmas también debemos hablar de su interrelación (de ahí lo que se sugiere, más adelante, al abordar la visión holística del arte).

El sostenimiento de un paradigma reside en la formación y manutención que proviene de una comunidad científica. Bajo un desarrollo dicho normal una investigación posee un perfil dogmático. Sin embargo, una nueva propuesta impone un trabajo de reinvestigación. La mente se adapta a un modelo determinado y así como la sociedad, cristalizando un dogma y sus "excepciones" o "anomalías" que son, por diversas veces, tratadas como tal. El problema es que tales "anomalías" se acumulan y urge que se rompa con los dogmas y se críe alternativas investigativas. Existe una pluralidad de teorías que impregnan un determinado paradigma, pudiendo o no ser aceptada.

Para los positivistas, por ejemplo, los paradigmas son inmensurables (no se puede compararlos ni dar ningún juicio de valor tal como "ese es mejor que el otro". No existe una comparación en que se pueda decir que dicha conquista científica es mejor que otra correspondiente. El contexto es otro, el campo es complejo y la contribución de cada estudio de referencia es diferenciada.

En la segunda mitad del siglo XX y principios del XXI fue establecida una epistemología de carácter histórico. La epistemología no es general pero sí - cómo ya 
señalado - son varias epistemologías con diversa pluralidad científica. La formación del Epistemólogo hay que transitar básicamente por la Ciencia y por la Filosofía, con ramificaciones en sus especificidades y necesidades de saber y construcción.

\section{Las ciencias y el concepto en la historia según Aristóteles}

Uno de los recursos argumentativos más eficaces utilizados por Aristóteles para explicar posibles verdades se expresa por el silogismo ${ }^{2}$ (en donde dos proposiciones contrapuestas llevan a una conclusión). Así, un silogismo para sostenerse debe partir irrevocablemente de la condición inmanente de una comparación en donde podemos tener por elementos dos o más sujetos, y estos con sus correspondientes objetos, fenómenos o espacios lo que nos lleva a concluir - a posteriori - que dicho recurso, al contemplar una de las partes de la relación con el hombre, se sostiene en una plataforma de consistencia y carácter social.

Si presupuesto aquí que ambos elementos comparativos del silogismo pueden esbozar una atmósfera social a partir del momento en que tales elementos son representados por la interacción de dos sujetos, de un sujeto con su medio o aún con una ideología, por cierto hay una relación cíclica en donde hombre y medio interaccionan influenciándose y siendo a la vez influenciados.

La explicación de tales relaciones y condiciones (harmónicas o no), además de la busca de soluciones, habita en el campo de las ciencias. En la amplitud clasificatoria de las ciencias, Aristóteles fundamenta las siguientes subdivisiones:

- Ciencias teóricas - racionalidades especulativas - ejemplo: ontología;

- Ciencias prácticas - racionalidades valorativas - ética y política - que priorizan valores;

- Ciencias productivas - medicina, arquitectura, poesía, música y otras pues se relacionan a la producción y esa, en consecuencia, mejora directamente la vida de las personas.

\footnotetext{
${ }^{2}$ Referenciado por Mannion (2008, p.41)
} 
Con todo, Aristóteles ya pensaba la relación que habría que encontrarse entre las tres ciencias, todo ello integrado. Los griegos pensaban que el cosmos era dotado de una racionalidad cósmica y de una cierta harmonía en que el hombre no debería interferir, eso para no afligir el equilibrio. Por eso la Filosofía de la naturaleza de los griegos está hecha objeto de cuestionamiento.

Podemos entonces creer y sostener en tres grandes ejes que parten desde esa filosofía de Aristóteles:

- Todas las ciencias anhelan, de cierto modo, la transformación del hombre y de su medio, y por eso, en un carácter más amplio, ellas están arraigadas en la misma esencia de primacía social. Se establece así a las ciencias sociales como ciencias de base;

- Debemos sí respetar a las especificidades. Sin embargo, la universalidad de un contexto puede ser mejor construida por medio de una estructura transdisciplinaria;

- La maturación y la evolución de una ciencia son incluso estimuladas por medio de una posición cuestionadora y no estanque. Eso lo podemos ejemplificar de manera más contundente a través de los planteamientos de una influyente corriente epistemológica del siglo XX bien representada por la dialéctica negativa de la Escola de Frankfurt.

Los hechos vivenciados por una persona en relación al espacio en que se encuentre y se percibe, además de estar ligado al reflejo de la colectividad, siempre ocurren bajo un contexto social, político y cultural. En esa relación de doble vía el ser humano dispone de característica ontológica elemental para ayudarlo a percibir su entorno, permeado por su idiosincrasia. Eso hace con que naturalmente las percepciones y concepciones de mundo de este ser sean infinitamente variadas - aunque en diversos momentos esté ecualizada por padrones sociales de comportamiento impuestos por las sociedades - pero que nos presenta como conclusión que lo que se busca no es la pura, simple y desinteresada verdad.

A lo largo de la historia - especialmente entre los siglos XIX y XX hasta nuestros días - diversos teóricos, filósofos, sociólogos, epistemólogos y educadores se han debruzado sobre estudios que les permitieran acercarse cada vez más a los ejes que sostienen el 
conocimiento de la Epistemología, centrados en tres cuestiones: ¿Qué es el conocimiento? ¿Qué debemos conocer? ¿Cómo conocimos lo que conocemos? (GREGO \& SOSA, 2008, p.16).

Los postulados construidos a través de los pensamientos filosóficos expresados por Donald Rumsfeld ${ }^{3}$ durante un discurso abordando la compleja cuestión de las fuerzas estadounidenses en el Iraq en 2003 son, por lo menos, instigadores de más atención y a la vez, por ser discutibles o controvertidos, nos remiten a las ideas - a veces tendenciosa - de la variación de significados y objetivos. En dicha declaración Rumsfeld dice que "[...] hay cosas que nosotros sabemos que no sabemos; sin embargo existen también [...] aquello que nosotros no sabemos que no sabemos" NORRIS, 2007, p. 31). El abordaje como ruta de salida alternativa, en doble vía, para cualquier consecuencia futura nos remite una vez más a la idea aquí propuesta de que los significados son, a lo mejor, algo de aspecto frecuentemente vuelto a determinadas intenciones.

Muchos son los puntos de vista, conceptos, aplicaciones e, inevitablemente, las polémicas o divergencias concernientes a las ciencias del conocimiento. Cada ser social termina por apropiarse de los más variados conceptos de forma a que se adecuen a lo que se busca, interesa o cree, y cada ser en la condición de "poseedor" de estos conocimientos lo transforma interpreta de modo a que se alcance determinados objetivos. Podemos permitir precedentes para un postulado sociopolítico a partir de las visiones positivistas de Comte en Brasil $^{4}$ inicialmente difundidas por Luis Pereira Barreto 5 y exteriorizadas, por ejemplo, en la emblemática frase en la bandera nacional brasileña: "Orden y Progreso" ${ }^{6}$, que en su cerne y génesis de intento, carga la misión de continuidad y solidaridad, es decir, la unidad en su más alta acepción, tal será su primer característico” (SOARES, 1998, p.98)

Surge una pregunta referente al demostrado y que puede incitarnos a una discusión de carácter sociopolítico muy incisivo: ¿Se ha convertido la visión positivista en una herramienta de control de las grandes masas una vez que crea una perspectiva de mundo y

\footnotetext{
${ }^{3}$ Ex-secretario de Defensa de EEUU. Ocupó el cargo de 2001 hasta 2006.

${ }^{4}$ Aludido en el Capítulo IV “A difusão do positivismo - Ingresso da doutrina no Brasil” del libro sobre el positivismo brasileño referenciado en este trabajo.

${ }^{5}$ Médico brasileño que vivió en el sig. XIX y que tuvo gran actuación cultural, médica y política en el país.

${ }^{6} \mathrm{La}$ contribución del positivismo para la República Brasileńa dónde la frase pasa a ser adoptada a partir del

"Decreto no 4 de 19 de novembro de 1889, projeto de Teixeira Mendes, com a cooperaçáo de Miguel Lemos [...]" (SOARES, 1998, p.98)
} 
futuro mejor en detrimento de las dificultades sociales y económicas, pasadas o actuales, de una comunidad, a alimentarse de falsas creencias y evitando así "ebulliciones sociales”? ¿Es tal vez una postura que limita como un ser (pseudo) consciente, pero no actuante dentro de una sociedad? Por la notoriedad de las situaciones y a causa del sentido común, tales cuestiones se muestran de cierta forma, retóricas.

Por lo que se nota a partir de la historia de las sociedades tenemos ejemplos latentes de esta práctica y que implica en tales valores. Retornando al ejemplo de la bandera brasileña, la frase que estampa dicho símbolo trae una propuesta interpretativa inicial rumo a la organización de una sociedad justa y al crecimiento en todos los campos que nortean la vida social. Con todo, bajo una evaluación más rigurosa, podemos concluir que la orden aquí establecida es la vigente e impuesta por los dominantes y el progreso viene sostenido por una falsa promesa en el intento de restar las presiones sociales consecuentes de las dificultades vivenciadas por las grandes masas. Hay aquí un caso emblemático de aplicación de determinados conceptos que se vuelven a intereses particulares en detrimento de la colectividad, lo que evidencia interpretaciones, intenciones y aplicaciones moldeadas bajo estas finalidades dominantes.

La búsqueda desinteresada por conocimiento y por la verdad una vez más se presenta, entonces, como un postulado puesto abajo cuando partimos, por ejemplo, de ese rápido paralelo entre los aspectos que involucran propósitos secretos tanto en el episodio protagonizado por Rumsfeld cuanto en la arquitectura del modelo positivista brasileño.

\section{Epistemología y educación: los objetivos truncados por la nobleza e por la perversión}

"El conocimiento es un estado altamente valorado en el cual se encuentra una persona en contacto cognitivo con la realidad. Por lo tanto, se trata de una relación" (ZAGZEBSKI, apud GREGO \& SOSA, 2008, p.153). En este vector conclusivo tal vez resida uno de los más grandes llamamientos al estudio de las relaciones sociales y consecuentes nuevas propuestas pedagógicas que abracen con más vigor la autonomía e interactividad del educando con su espacio escolar. 
Al abordar la esfera educacional, por ejemplo, FREIRE (1987; 1996) resalta con adecuado abordaje la cuestión de la esencia de este conocimiento, que debe estar siempre ligada a la idea de construcción de unas herramientas que proporcionen el crecimiento y la libertad del individuo y en dónde sus parámetros de adquisición sean norteados por la transparencia en su acceso, contextualización de la realidad, formación de sentido crítico, capacidad de autoevaluación como ser humano y social, además de la posibilidad de toma de posición. La evolución del papel social de cada ser y de la mayor o menor interacción entre sus pares depende del hecho de que seres humanos están siempre frente a frente a través del vínculo de la palabra y del afecto plenamente humano.

Hay una estrecha relación entre la filosofía, el poder y la educación, lo que también demuestra un perfil semejante a lo que fue supra citado en la ligación entre el poder legalmente constituido ante las grandes masas sociales. Hay diversos textos y libros que demuestran tal conexión cíclica así como las prácticas educacionales cristalizadas que vienen condenando la escuela a perpetuar largos fracasos por cuenta de las imposiciones que se constituyen cómo la égida paradigmática para la imposición de los conceptos verticales, a preterir los deseos y la individualidad de los educandos.

Foulcaut expone en las líneas iniciales de su consagrada obra Vigiar e punir ${ }^{7}$ un severo y hediondo ejemplo de punición sangrienta partiendo después para otro, ahora disciplinador sobre un presidio ligado a la rutina cronometrada, paralelizando "suplicio y utilización del tiempo" (FOCAULT, 2004, p.11) en donde complementa: "Ellos no sancionan los mismos crímenes, no punen un igual género de delincuentes. Mas definen bien, a cada uno de ellos, un cierto estilo penal". Dicha cualidad preserva una condición doctrinaria muy oportuna para el paradigma de la escuela que se hizo presente a lo largo de muchas décadas y que aún nortea a muchas prácticas de clase en lo que toca a la disciplina de los alumnos, vueltos a la pura obediencia de reglas, normalización y adiestramiento tal cual lo percibimos en el siguiente trozo de la obra de Foucault (1998, p. 125-126).

A ordenação por fileiras, no século XVIII, começa a definir a grande forma de repartição dos indivíduos na ordem escolar: filas de alunos na

\footnotetext{
${ }^{7}$ FOUCAULT, Michel. Vigiar e punir - Nascimento da prisão. Tradução de Raquel Ramalhete. 29a Edição, EDITORA VOZES, Petrópolis, 2004
} 
sala, nos corredores, nos pátios; colocação atribuída a cada um em relação a cada tarefa e cada prova; colocaçáo que ele obtém de semana em semana, de mês em mês, de ano em ano; alinhamento das classes de idade umas depois das outras; sucessáo dos assuntos ensinados, das questóes tratadas segundo uma ordem de dificuldade crescente. E nesse conjunto de alinhamentos obrigatórios, cada aluno segundo sua idade, seus desempenhos, seu comportamento, ocupa ora uma fila, ora outra; ele se desloca o tempo todo numa série de casas; umas ideais, que marcam uma hierarquia do saber ou das capacidades, outras devendo traduzir materialmente no espaço da classe ou do colégio essa repartição de valores ou dos méritos. Movimento perpétuo onde os indivíduos substituem uns aos outros, num espaço escondido por intervalos alinhados.

Se supone que una de las palabras de orden que construye el 'interlink' entre filosofía, poder y educación es la ideología. ROMERO, en su artículo intitulado "Para uma nova construção discursiva da autonomia" (LECHINI; KLAGSBRUNN \& GONÇALVES, 2009, p.55) ejemplifica tal proposición de forma oportuna al citar que

\footnotetext{
la autoridad escolar en tanto significante flotante fija su significado en la particularidad, detiene sus múltiples desplazamientos posibles cuando se encuentra amarrada a un punto nodal - en este caso, la dimensión civilizatoria de la educación moderna o la propuesta científicopedagógica - para constituirse en parte de una red de significados que define una identidad ideológica.
}

La reflexión y el debate que circundan a la capacidad que un individuo puede ejercer de autogobernarse desde el uso de su privilegio de ser social y agente de la construcción de una colectividad más igualitaria se alarga en otros análisis de abordaje filosóficamente enraizado, que no se agota bajo el contexto puramente educacional, corporificando su nobleza delante del colectivo.

Stangroom \& Garvery (2009) nos recuerdan cómo Locke justifica la autonomía y la individualidad como condición humana irrevocable, por ejemplo, delante de los axiomas cuando "asume que la doctrina de las ideas innatas implica en que debe haber ideas o principios con los cuales todo el mundo concuerda, y él argumenta que no existe tal concordancia universal" (p.73). Con todo, Mannion (2008) al situarnos sobre el pensamiento del contrato social defendido por Locke fatalmente remonta el escenario actualmente presenciado por muchos que tal contrato es sumariamente roto pretiriendo las 
mejorías que pueden ser ofrecidas a la colectividad, sosteniendo el atasco de los objetivos epistemológicos y conduciendo a la perversión sociopolítica.

Hume niega la esencia ontológica de la individualidad, mas, debido a la evidente influencia de Locke, admite bajo carácter epistemológico que no podemos estar rendidos a verdades absolutas (Mannion, 2008), por lo que reafirmo aquí lo ya postulado en diversos escritos y también ya referenciado en cierta medida en este cuerpo monográfico, y que tal utópica y maquillada verdad, legitimada e instituida por el poder legalmente constituido (diversas veces de forma escusa) no puede tener notoria e irrevocable validez, siendo conducida por unos pocos que dictan de forma indiscutible a los patrones de actitudes y comportamientos de un cuerpo colectivo. De ahí el porqué de la incansable discusión que envuelve la tríade educación versus ser social versus autonomía.

Durkheim reafirma que, en dado momento, la sociedad ha considerado como parámetro una educación impuesta por sus individuos, centrada en un ideal humano. Aquí se erige una vez más una oportunidad para engendrar en las manos de inescrupulosos políticos la perversión de la educación y afines. Varsavsky (1969) ejemplifica y contextualiza eso muy bien en las esferas superiores, lo que hacen y de lo que se nutren - en términos objetivos -las investigaciones científicas, sobre todo en los países de tercer mundo cuando se alimenta una creencia (aunque de forma velada) de que un investigador de prestigio es lo que más produce y no lo que efectivamente contribuye con la sociedad. Eso engruesa la justificativa de una pobreza generalizada en las investigaciones sobre ciencias humanas en términos de resultados. En verdad, lo que se ve aquí es un camino para la perversión como herramienta estratégica.

Bajo otra mirada sobre la reconstrucción de los valores que moldean el comportamiento del ser social, Kant piensa que para el conocimiento hay elementos fundamentales como la forma y la materia. La materia se constituye sola, a partir de un elemento en desorden, caótico, que necesita organización. La forma pasa por la sensibilidad y por el sujeto. Tal sujeto es lo que llamamos transcendental, transportador de la condición formal e para la condición formal. La epistemología contemporánea posee mucho de la visión de Kant. 
Sobre la modernidad cabe comentar que esta es constantemente 'bi-frontal', o mejor, con muchas frentes de creencia y observación. Destacar el valor de un individuo significa desprenderse de otro cualquier valor dogmático en detrimento del libre pensamiento de cada ser. La propia constitución y desarrollo de la dialéctica sería un ejemplo.

\section{En la esfera de la educación y democracia según Dewey}

Según Dewey (1916), si afirmamos que la educación como función social conduce el individuo inmaturo al conocimiento y que con ella este individuo puede desarrollarse en la sociedad, eso equivale a decirnos que la educación tiene que variar de acuerdo con la cualidad de vida predominante en el grupo. Hay diferentes normas, por ejemplo, para grupos que anhelan cambios y desarrollo en detrimento de aquellos que simplemente desean preservar sus costumbres.

Al describir el concepto de sociedad se destaca el hecho del hombre estar ligado a diferentes grupos sociales en donde los componentes pueden ser muy diferentes. Dentro de un grupo social vemos que existen grupos menores bien distintos que no están por veces tan unidos como una comunidad general y llenada de las mismas acciones y pensamientos. Sociedad y comunidad son elementos ambiguos.

“Toda educación dada por un grupo está inclinada a socializar sus miembros, pero la cualidad y el valor de la socialización dependen de los hábitos y aspiraciones del grupo" (DEWEY, pág. 4, 1916, Cap. VIII).

No se debe, con todo, ir a dos extremos: uno es la búsqueda de una 'sociedad ideal'. Se debe, sí, una sociedad de entre lo que ya existe pero sin caer en el otro extremo y que es repetir las características ya cristalizadas, pero sí extraer y destacar aquellas deseadas y rechazar críticamente a las no deseadas, sugiriendo mejorías.

Un grupo no puede aislarse completamente, aunque tampoco mantenga unas cooperaciones e interactividades perennes; pues varía de acuerdo con los valores, intereses e influencias de otros grupos. 
Existe en esa relación el ejemplo del gobierno déspota que conduce su pueblo por medio del terror. No se actúa solamente por el temor absoluto. Las autoridades deben adecuarse a las "actividades congénitas de sus súbditos" para gobernar.

Pero en dicha relación no hay un número extenso de intereses comunes entre los grupos sociales, ni el desarrollo y retroceso entre los miembros del grupo social (¿diríamos una resistencia, un cierto aislamiento y homogeneidad de comportamiento?). Estímulo y respuesta son excesivamente unilaterales (¿dificultades en la escuela?). La busca aquí apunta hacia la 'endosmosis' social (homeostasis social).

Para tenerse un gran número de valores en común, hay que tenerse cualidad equitativa sobre la oportunidad de adquisición de dichos valores por el grupo. La falta de libre intercambio también condena el grupo a no conquistar la homeostasis social.

Diferentes clases se disponen a tener los mismos problemas de orden social aunque en los estratos más favorecidos económicamente eso queda menos evidente.

Y ¿cómo eso pasa y es reforzado - infelizmente - en la escuela? Bien, si una de las condiciones de esa 'homeostasis social' es el libre intercambio entre grupos, la escuela, en diversos momentos, no está siendo el mejor ejemplo para fomentar tal actividad en el quesito provocar estímulos intelectuales. Cuando se cambian experiencias bajo ese intercambio, se descubre el nuevo y cuando se descubre el nuevo nos vemos ante la oportunidad (y necesidad) de pensar. Pero, ¿Cómo hacerlo si la escuela está inclinada a limitarse en actividades cerradas y que no incitan dicho intercambio?

En un conjunto de grupos sociales distintos no hay un gran número de intereses en común (las respuestas de cada grupo son, en general, unilaterales) y para que si amplíen los valores en común de los grupos se debe garantizar cualidad y equidad acceso a estos valores (Dewey, 1916).

La segregación de grupos y el cercenamiento del libre intercambio suele agravar esta situación, improductiva para los grupos. Bajo esta situación, la conducción de una clase queda centrada en una rutina enfadosa y sin sentido, lo que se configura como una desventaja para el pobre y arbitraria para el rico pues crea una relación servil. Lo que se le transmite, lo menos favorecido lo acepta sin al menos saber de qué se habla, lo que crea algo aún peor: pasa a aceptar que el otro 'superior' acabe por dictar a su conducta (lo que, bajo 
una visión platónica, le pone en una condición tal cual un esclavo). ¿Podemos comparar a lo que llamamos hoy clase popular con lo que llamamos 'masa de maniobras'? ¿Eso explica el porqué de las grandes masas que se dejan estar pasivamente sojuzgadas en el perverso paradigma referenciado por Foucault sobre la vigilancia y la punición culminando por consiguiente con la aceptación y el adiestramiento?

Un ejemplo de eso es cuando un determinado grupo considera a una determinada área de conocimiento como útil aunque no comprenda su utilidad y ni demuestre personal interés por ella. Es como la poco comprendida, discutida y visualizada acción del operario en una industria por el propio operario, sobretodo en un sistema estandarizado.

La inteligencia se torna meramente mecánica, con ausencia de espíritu y vida emocional distorsionada. Una realidad así nunca va atingir al alumno visando a una transformación.

El aislamiento y la exclusividad de un grupo revelan un carácter antisocial cada vez más frecuente: familias que se aíslan de vecinos, escuelas de comunidades, pobres versus ricos, etc. Dicha estructura formal y rígida intenta justificarse por el hecho de la 'preservación de culturas y costumbres de un grupo' lo que caracteriza una postura naturalmente egoísta y que compromete más intensos contactos e intercambios sociales (algunas tribus salvajes llegan a considerar como sinónimos a 'extranjeros' y 'enemigos').

Hasta una guerra entre dos naciones muestra por lo menos una ventaja para las relaciones entre diferentes grupos: accidentalmente se conocen e interaccionan, aunque por contingencia, y luego terminan por ampliar a sus horizontes.

Estos puntos se dirigen hacia la democracia pero pueden generar dos situaciones distintas: la búsqueda por intereses comunes o el reconocimiento de tales características como forma de control social. Otro factor importante reside en la libre interacción entre los grupos (en detrimento al natural aislamiento) para cambios de hábitos sociales y reajuste continuo a través de las nuevas situaciones provenientes de ese intercambio.

El hombre solamente puede crecer e interaccionar en un espacio democrático. Y no solamente de gobierno, pero sí en una esencia más profunda que es la participativa, y si tiene condiciones de romper barreras que impidan el intercambio de grupos, de ideas, de exposición desde el punto de vista de cada uno y del libre pensar asegura beneficiarse a sí 
mismo y al grupo con sus acciones. Se asegura una liberación de las capacidades del individuo que permanecen por diversas veces reprimidas.

\title{
5. El arte y la comunión de paradigmas - propuesta
}

\begin{abstract}
As visóes metafísicas e religiosas do mundo perderam o valor e criou-se um desencantamento terreno de mundo, alimentado pelo capitalismo, pelo senso pragmático e pela mudança de valores centradas nas coisas, nas posses, valores distorcidos. Os conflitos sociais aumentam e também as contradiçóes, choques, exploraçóes e críticas das ideologias. (Profa $\mathrm{Dr}^{\mathrm{a}}$ Esther de la Kóbila - janeiro 2010; Seminário de Epistemologia - UNR)
\end{abstract}

Evocamos nuevos cuestionamientos aglutinando el pensamiento de la Dra Kóbila así como los intentos norteados por el hacer artístico como alternativa para la construcción de la autonomía por medio de su subjetividad.

¿Puede el arte a través de múltiples lenguajes conducir el apreciador a una reflexión maximizada de su existencia en cuanto ser social y actuante? Debido a su carácter de impactante penetración, poder de persuasión y pureza estética, creemos que sí. Como presupuesto nos muñimos de las posibilidades artísticas no sólo como artefacto de exteriorización de lo que percibimos y sentimos en el mundo, pero también como herramienta realizadora de anhelados ideales por una vida mejor, por una sociedad mejor y por un mundo mejor. Pensar y querer son sí los primeros pasos para los que realmente intenten planear y transformar.

Parafraseando Elliot (2004), el 'Arte y la creación de sentido' son, respectivamente y por consecuencia, área de conocimiento y objetivo. Es este último que puede fomentar el pensamiento rumo a la transformación. Cuando Elliot se nos alerta que "los programas de educación artística deberían intentar fomentar el desarrollo de la inteligencia artística” (2004, p.65), eso nos lleva a la conciencia de que debemos, en un primer paso, construir el real concepto de esa inteligencia que, ante lo ya citado en este trabajo, no hace sentido que sea puramente técnica, sin espíritu y sin vida. El primer principio defendido por él reside en la preservación de las especificidades, aunque no se puedan agotar en ellas mismas si direccionadas a la reproducción técnica, prescindiendo de una amplitud de formación para el alumno de Educación Artística. 
En ese sentido, podemos buscar como aporte a las ideas sobre Aprendizaje Transformativo referenciadas por investigadores, destacándose las obras de Mezirow (1991) y Cranton (1994). Tal propuesta de paradigma - direccionada especialmente para alumnos adultos - prevé una posibilidad más alargada de formación a partir de contenidos específicos, pero de forma holística y buscando una formación más completa, contextualizada, interactiva y de valoración de la autoestima del educando.

Los educadores como estudiantes transformativos o en camino para convertirse en educadores transformativos cuentan con pocos recursos literarios sobre cómo pueden obtener ese perfil y cambiar a su práctica, como nos señaliza Boice (apud Cranton, 1994). Cranton Levinson-Rose y Menges (1981 apud Cranton, 1994) aún advierten que la mayoría de las experiencias son naturalmente superficiales si tomas como aporte unas técnicas específicas y encuentran refugio en el aislamiento de cualquier contexto más amplio o de la teoría en la práctica. Aquí nos viene la reflexión de que no se puede intentar la simple construcción de un 'manual de aprendizaje de adultos' en detrimento de la libertad de expresión, acción y autoevaluación reflexiva en que cada grupo investigado y cada integrante tiene su idiosincrasia. Lo importante también en ese proceso es lo que se hace presente en las palabras de Clark (1992, p.17 apud CRANTON; 1994, p. 213) al elucidar que:

\footnotetext{
nós temos que observar primeiro nossa luta em criar um mecanismo a partir de nossas próprias experiências...e aprender nosso processo de aprendizagem...tendo observado atentamente nosso próprio processo de aprendizagem e por conseqüência o processo de qualificação de significados nós estaremos em posição de facilitar este processo em outras pessoas
}

Mezirow evidencia que este punto de la individualidad perceptiva como elemento de relevancia, al puntuar que "nuestras perspectivas de significado filtran el modo por lo que nosotros proyectamos nuestro simbólico imaginativamente para interpretar lo que es presentado a los nuestros sentidos" (Mezirow; 1994, p.38), nos sugiere que cada interpretación personal también connota diferenciadas cargas de valores que pueden ser cambiantes conforme la manera por la que son abordadas y ofrecidas. En la práctica, si trabajamos determinado lenguaje alcanzando mayores expectativas de las que cada 
educando cree tener valor en su vida práctica, social y personal y es aprehendida con más cuidado, luego tendremos como alternativa un lenguaje verdaderamente significante para cada estudiante.

Abajo hay dos trozos de canciones en que una muy breve contextualización con la historia de Brasil, en el periodo de la dictadura y pos dictadura, ilustran con propiedad este escenario de llamamiento a la reflexión y acción transformadora por medio del arte:

\section{Cálice - Chico Buarque}

Como beber

Dessa bebida amarga

Tragar a dor

Engolir a labuta

Mesmo calada a boca

Resta o peito

Silêncio na cidade

Não se escuta

De que me vale

Ser filho da santa

Melhor seria

Ser filho da outra

Outra realidade

Menos morta

Tanta mentira

Tanta força bruta...

Pai! Afasta de mim esse cálice

Pai! Afasta de mim esse cálice

Pai! Afasta de mim esse cálice

De vinho tinto de sangue... 
La composición del cantautor Chico Buarque muestra de forma latente el estado de represión explícita y severa a la libre expresión de un pueblo que está cerceado por las corrientes de la dictadura militar instituida en Brasil después del golpe de 1964. Delante de la dificultad en promover acciones concretas plenamente incisivas rumo a la liberación frente a la moral y a regímenes impuestos, el arte se convirtió en un estratégico y eficaz recurso para impeler a una conciencia activa argumentando sobre la necesidad de la ruptura de un modelo vigente. Los cambios en ese sentido no nacerían necesariamente de un ímpetu revolucionario, pero germinaría a través de una más construcción del introspectivo individual que, al solidificarse lo suficiente, podría erguirse al nivel de actitud corporificada en defensa de la individualidad y de la colectividad.

\section{Perfeição - Renato Russo \\ Vamos celebrar \\ A estupidez humana}

A estupidez de todas as naçóes

O meu país e sua corja

De assassinos

Covardes, estupradores

E ladrōes...

Vamos celebrar

A estupidez do povo

Nossa polícia e televisão

Vamos celebrar nosso governo

E nosso estado que náo é naçáo...

Celebrar a juventude sem escolas

As crianças mortas

Celebrar nossa desuniáo...

[...] 
El periodo subsecuente a la dictadura militar es marcado en definitivo en 1985 en donde, por medio del voto indirecto de un colegio electoral, Tancredo Neves ${ }^{8}$ se convirtió en el primer presidente electo y no militar de la República pos dictadura. Este fue un momento de alivio a la libertad de expresión de un pueblo y una relativa conquista de la democracia. Algunos años antes, famosos grupos de rock - que aún permanecen en el escenario musical brasileño - usaron de sus posibilidades artísticas aliadas a un momento oportuno y constituyeron la química ideal para su conversión en referencia entre los jóvenes de entonces. Grupos como Titâs, Paralamas do Sucesso e Legião Urbana, agregaron en las letras de sus canciones muchos pensamientos que estaban hace mucho tiempo 'atragantados' en las gargantas del pueblo y no podrían ser expresados hasta la década anterior. Tal poder transformador del arte ya era conocido por los militares y se muestra evidente tal conocimiento si visualizamos históricamente hechos comprobadores como la decisión de retirarse de las salas de clase a los experimentados artistas de atelieres para remplazarlos por docentes no habilitados alegando 'necesidad de formación en magisterio' o aún en actitudes más incisivas como arañar a ciertas fajas sonoras en determinados discos grabados por grupos que expusieran en sus letras algún tipo de crítica al régimen y hasta los mismos artistas eran detenidos en sus festivales de música brasileña por osaren exponer letras consideradas 'subversivas' o 'perturbadoras del orden'.

Entretanto, el momento del arte musical aquí presentado pertenece a un contexto más reciente, en donde el país ya pasaba por los problemas de esa 'nueva democracia' en varios quesitos como el social, el político y el económico. La composición de Renato Russo, ex vocalista del grupo Legión Urbana9 intenta mostrar que a todos cabe la misión de ser críticos, pero también autocríticos, pues los problemas sociales son consecuencia de actos insanos con los cuales de cierta manera - consciente o inconscientemente - pactamos en

\footnotetext{
${ }^{8}$ Primer presidente brasileño elegido por el pueblo a través de voto directo y secreto. Falleció en este mismo año victimado por complicaciones resultantes de una cirugía abdominal, siendo entonces remplazado por su vice, el actual senador de la República José Sarney.

9 'Entraram em cena acelerando o andamento da música jovem brasileira. Com ares punks e guitarras distorcidas, assumiam a voz daqueles que tinham crescido sobre o período militar chamando-os de "Geração Coca-Cola”, num texto que punha o dedo na cara dos mais velhos, sem deixar de cutucar a própria ferida. Um misto de desabafo e autocrítica que náo poupava ninguém'. Trecho retirado do site oficial da banda que mostra o perfil citado neste trabalho e incorporado pelo grupo. Os integrantes se reuniram de forma efetiva no final dos anos 70 e a banda se consolidou nos início dos 80. Disponible en: http://beta.legiaourbana.com.br/biografia?pagina=01. Accesado en junio de 2010.
} 
nuestro día a día. Podemos sí en esta demostración considerar que es una consciente oportunidad de alimentarse del hacer artístico para que en una propuesta pedagógica esa formación vuelta a la construcción plena del ser social crítico y actuante sea realmente puesta al servicio.

\section{La metodología del aprendizaje transformativo e la pedagogía libertadora en el arte.}

Sería de una pretensión desmedida si decidiéramos osar exponer en pocas líneas de este ensayo toda una fundamentada propuesta metodológica. En verdad ya fue aquí elucidada una intención inicial de abrirse espacio para discusiones que apunten para este norte y que abracen todas las iniciativas posibles en la construcción de una educación realmente emancipadora.

Se toma aquí la libertad de apropiación de este término ricamente utilizado por Freire (1996), pues en sus exposiciones acerca de esa necesidad inmanente a la construcción de un ciudadano, él aclara para nosotros que en ese sentido tenemos ahora mayor noción de que el alumno sin su debido espacio para expresarse y formar parte de su propia construcción como ser humano y ciudadano, se convierte en un individuo vaciado de ética en su sentido más amplio y universal en donde ahí se puede ofrecerle la posibilidad de no verse a sí mismo cogido por un discurso fatalista casi prioritario en la era neoliberal. Más que un espacio de expresión, el alumno puede entrever en esa propuesta - aliada a los lenguajes artísticos como fomentadores y facilitadores - un espacio para cambios, rumo a la transformación social a favor de una mayoría y de sí mismo.

Existe una necesidad indispensable para una reflexión crítica sobre una práctica y la relación teoría/práctica. Dicha reflexión puede ocurrir yuxtapuesta a la de los alumnos en las discusiones, producciones y observaciones sobre el arte y sus obras en el cotidiano escolar y eso también forma parte del perfil de un verdadero formador: lo que en oposición a la transferencia vertical de conocimientos propone en verdad formativa a una autoconstrucción de saberes para todos lo que están en eso involucrados. 
Bajo un contenido erguido por la ética en las relaciones interpersonales, el espacio de construcción del ser, partiendo del propio ser y de su postura participativa en interacción de grupo surge cuando Freire (1996, p.16) dice

\footnotetext{
$\mathrm{Na}$ verdade, seria incompreensível se a consciência de minha presença no mundo não significasse já impossibilidade de minha ausência de construção da própria presença. Como presença consciente no mundo náo posso escapar à responsabilidade ética no meu mover-me no mundo. Se sou puro produto da determinação genética ou cultural ou de classe, sou irresponsável pelo que faço no mover-me no mundo e se careço de responsabilidade, não posso falar de ética
}

La metodología cuantitativa es materia compleja para que sea aplicada aisladamente en el estudio social una vez que este se compone de sujetos y significados, luego es conveniente considerar que una posible eficacia debe partir también de una evaluación cualitativa. Sin embargo, es importante evidenciar que no se reconoce un método único en cualquier investigación pero sí líneas metodológicas. Aquí, esencialmente se fija en una primera y futura objetivación los conocimientos metodológicos delineados por el aprendizaje transformativo de Mezirow (1991) y Cranton (1994), las proposiciones de la pedagogía libertadora de Freire $(1987 ; 1996)$ y los propósitos de la propia metodología cualitativa - estos como antes esbozados en la arquitectura lacónica de este ensayo.

Dentro de la investigación científica hay una premisa de que la crítica es fundamental. Gran parte de la historia de la Ciencia está hecha de críticas y contradicciones, o sea, una metodología construida hoy puede (y muchas veces debe) sufrir críticas, alteraciones, adecuaciones y evolucionar en nuevas teorías para la busca de respuestas.

\section{Conclusión}

Con notoria certeza basada en investigaciones, estadísticas y hasta mismo expresada por el sentido común, concluimos que nunca en la historia de la humanidad el ser humano tuvo un acceso tan facilitado y diversificado a la información y al conocimiento. Sin embargo, verificamos en el otro extremo una frecuente rendición del ser social a paradigmas 
cristalizados por la acomodación de óptica fatalista, por falta de homeostasis y maturación crítica de nuevos caminos o aún los más preocupantes y nocivos designios de una lógica neoliberal que nutren, en una progresión geométrica, a una estratégica dicotomía favorecedora de la distancia entre los que detienen el poder y la gran mayoría que aún se comporta pasivamente sujetándose a los preceptos de los primeros. Urge el rescate de una sociedad que ruma en una búsqueda misionera por condiciones igualitarias de sobrevivencia y dignidad delante de una de las mayores crisis de la humanidad tan pronunciada por el alejamiento entre toda la producción de conocimiento - que es la mayor de la historia universal concentrada tan sólo en los últimos cien años - y por otro lado tenemos las llagas sociales que en la misma intensidad remontan a las trágicas y recordistas estadísticas con números asoladores de hambre, miseria, desigualdad y exploración de la colectividad.

La transformación de la humanidad solamente puede partir, efectivamente, de acciones de la propia sociedad y la institución escolar tiene como obligación y prerrogativa, en la condición de locus del saber y de la ética, lanzarse pioneramente usando de reales providencias acerca de la conversión de cada ser humano para que este se responsabilice por la reconstrucción de su universo norteado por la justicia y salvación de la humanidad.

\section{Bibliografía}

CRANTON, Patrícia. Understanding and promoting transformative learning: a guide for educators of adults / Patrícia Cranton - 1st ed. ISBN: 0-7879-0017-6, Jossey-Bass Company, 1994.

DEWEY, John. Democracia y Educación - una introducción a la filosofía de la educación. Tradução de Lorenzo Luzuriaga. 1ª.ed., Ediciones Morata, Madrid, 1995.

ELLIOT, W. Eisner. El arte y la creación de la mente. El papel de las artes visuales en la transformación de la consciencia. Paidos, 2004

FOUCAULT, Michel. Vigiar e punir - Nascimento da prisão. Tradução de Raquel Ramalhete. 29.ed., Editora Vozes, Petrópolis, 2004 
FREIRE, Paulo. Pedagogia da autonomia: saberes necessários à prática educativa / Paulo Freire. - São Paulo: Paz e Terra, 1996 (Coleção Leitura)

FREIRE, Paulo. Pedagogia do oprimido: 17a edição / Paulo Freire. - São Paulo: Paz e Terra, 1987

GREGO, John; SOSA, Ernst. Compêndio de Epistemologia. Tradução de Alessandra Siedschlang Fernandes e Rogério Bettoni. São Paulo: Ediçóes Loyola, 2008

LECHINI, Gladys; KLAGSBRUNN, Vitor; GONÇALVES, Willian. Argentina e Brasil vencendo preconceitos: as várias arestas de uma concepção estratégica. Rio de Janeiro: Revan, 2009

MANNION, James; O livro completo da Filosofia: entenda os conceitos básicos dos grandes pensadores: de Sócrates a Sartre. Tradução Fernanda Monteiro dos Santos. 5.ed. São Paulo: Madras, 2008.

MEZIROW, Jack, date. Transformative dimensions of adult learning / Jack Mezirow. ISBN 1 - 55542 - 339 - 6, Jossey-Bass Company, 1994.

NORRIS, Christofer. Epistemologia: conceitos-chave em filosofia. Tradução de Felipe Rangel Elizalde. Porto Alegre: Artmed, 2007.

SOARES, Mozart Pereira. O positivismo no Brasil: 200 anos de Auguste Comte. Porto Alegre: AGE: Editora da Universidade, 1998.

STANGROOM, Jeremy; GARVEY, James. Os grandes filósofos. Tradução André Oides. Sáo Paulo: Madras, 2009.

VARSAVSKY, Oscar. Ciencia, política y cientificismo. Centro Editor de América Latina, Buenos Aires, 1969. 